NOTE

\title{
Parasite host relations: Hexamita salmonis in rainbow trout Oncorhynchus mykiss
}

\author{
A. Uldal, K. Buchmann* \\ Department of Veterinary Microbiology, Section of Fish Diseases, Royal Veterinary and Agricultural University, 13 Bülowsvej, \\ DK-1870 Frederiksberg C, Denmark
}

\begin{abstract}
The relationship between host size and infection, the site selection in the host and the association between health status and infection were studied in Hexamita salmonis (Moore, 1923) infected rainbow trout from commercial trout farms. During a $1 \mathrm{yr}$ survey it was shown that the flagellates occur primarily in the smallest fry. The site occupied by the parasite is preferentially the pyloric region and the anterior intestine but in heavily infected fish the parasites occur throughout the entire length of the gut. Infected fish exhibited significant anorexia and significant body weight reduction
\end{abstract}

KEY WORDS: Diplomonadida - Hexamita salmonis - Rainbow trout - Oncorhynchus mykiss . Site selection - Body weight reduction · Host size

The diplomonadid intestinal flagellate Hexamita salmonis (Moore, 1923) infects salmonid hosts and has been recorded in a large number of disease surveys (Moore 1923, Zitnan \& Cankovic 1970, Ferguson 1979. Rosengarten 1985, Poynton 1986, Lom \& Dykova 1992, Buchmann et al. 1995, Woo \& Poynton 1995). Various theories about this parasite's biology and pathogenicity have been proposed (Moore 1923, Davis 1956 , Uzmann \& Hayduk 1963, Uzmann et al. 1965). However, only a few studies have actually provided us with clear evidence of host infection, site selection and association with pathological conditions. The present paper provides basic data on these issues in rainbow trout from Danish fish farms.

Materials and methods. Fish: All fish used in the present investigation were obtained from a Danish freshwater trout farm where only commercial trout feed is offered. Fish were weighed and lengths measured before examination for parasites.

Infection in relation to host size: In 1994 a total of 502 rainbow trout with body lengths ranging from

-Addressee for correspondence.

E-mail: kurt.buchmann@vetmi.kvl.dk
2.5 to $27.5 \mathrm{~cm}$ were examined for infection with Hexamita salmonis by microscopic 100-400× magnification of intestinal contents.

Microhabitat selection: From a single hatchery fish tank a total of 47 specimens of infected fry (mean length $4.1 \mathrm{~cm}, \mathrm{SD} 0.3$ ) were sampled. The intestine of each fish was divided into 4 parts (pyloric region, anterior intestine, midpart and hindpart), and the infection level in each part was noted. Each part was cut open and pressed between a slide and cover slip and examined under the light microscope. The maximum number of flagellates observable at $400 \times$ magnification (field area $0.62 \mathrm{~mm}^{2}$ ) was expressed according to 3 categories: (1) 1 to 5 flagellates; (2) 6 to 40 flagellates; (3) more than 40 flagellates.

A total parasitological examination of all fish was conducted (data not shown).

Association between infection, gut content and fish size: A sample of 35 fry (mean length $5.5 \mathrm{~cm}, \mathrm{SD}=0.8$ ) reared together from the yolk sac larval stage in another hatchery fish tank were examined for infection. The contents of the stomach and intestine were characterized as empty or as containing food. In addition, the presence of a characteristic yellow intestinal mucus was noted. The total body lengths and body weights of examined fish were recorded.

Statistics: Differences between groups were statistically evaluated using a 1-way analysis of variance (ANOVA).

Results. Hexamita salmonis occurs primarily in smaller fishes. In the smallest size group (fish with body lengths from 2.5 to $7.5 \mathrm{~cm}$ ) $70 \%$ were infected, whereas only 10 and $2 \%$ were infected in the second (7.5 to $12.5 \mathrm{~cm}$ ) and the third (12.5 to $17.5 \mathrm{~cm}$ ) size groups, respectively (Fig. 1). No infection was seen in larger fish.

In lightly infected fish (Category 1) Hexamita salmonis occurred significantly more often (ANOVA 


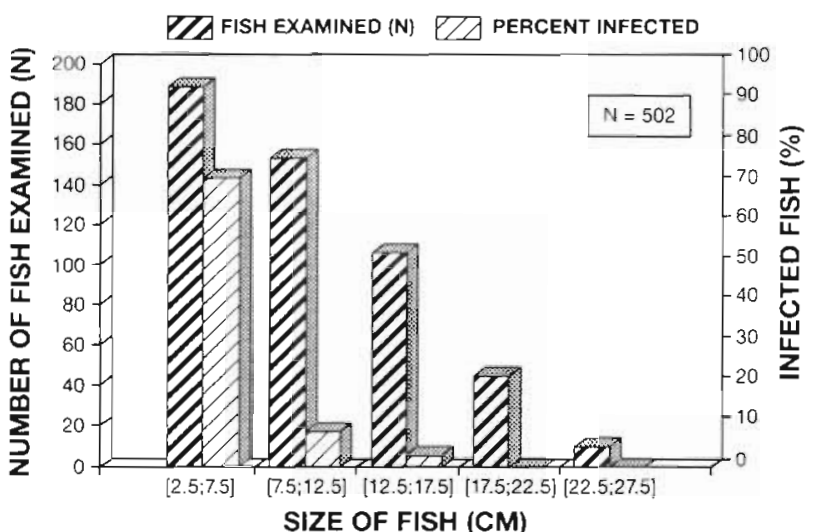

Fig. 1. Hexamita salmonis infecting Oncorhynchus mykiss. Relationship between host size and $H$. salmonis infection in rambow trout

$p<0.001$ in the pyioric region and the anterior intestine than in the mid-and hindpart of the intestine. This is also the case for Category 1 and 2 (ANOVA $p<0.01$ ). In contrast, when heavily infected fish are included (Category 1,2 and 3), the entire length of the intestine is occupied (Fig. 2). No other parasites were found in the intestinal tract, and no $H$. salmonis flagellates were recorded in extraintestinal sites.

Hexamita salmonis infection was associated with reduced weight and length. The uninfected fry with a mean body weight of $2.83 \mathrm{~g}$ (SD 1.17) were heavier compared to infected fish with a mean body weight of $1.03 \mathrm{~g}$ (SD 0.64) (ANOVA p < 0.0001). A similar difference was recorded for body length in the 2 groups (Fig. 3).

This reduced size is associated with anorexia. The frequency of empty gastrointestinal tracts and the presence of yellow mucus in infected fish was significantly higher than in uninfected fish (Fig. 4).

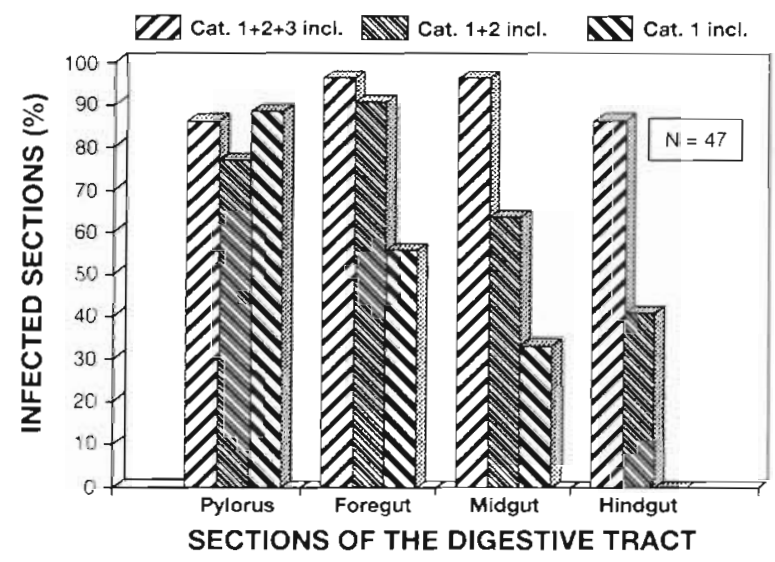

Fig. 2. Hexamita salmonis infecting Oncorhynchus mykiss. Microhabitat selection of $H$. salmonis at various infection intensity categories in the intestine of rainbow trout

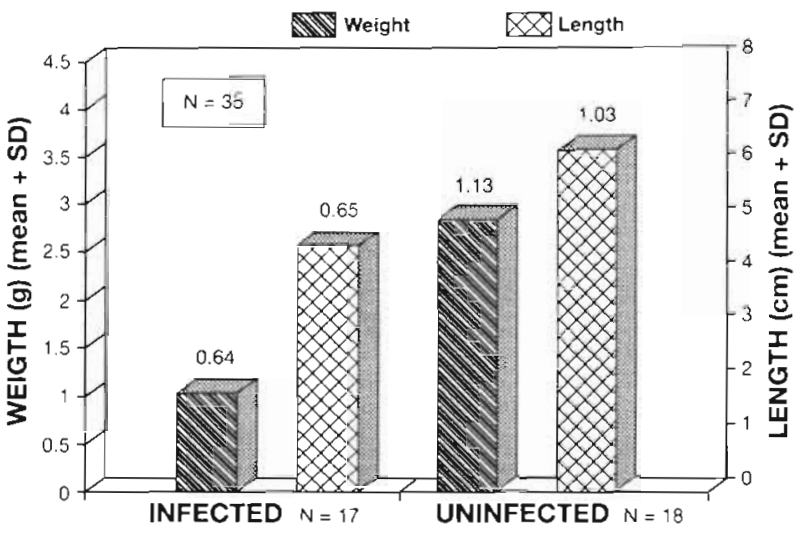

Fig. 3. Hexamita salmonis infecting Oncorhynchus mykiss. Comparison of rainbow trout weight and length values in relation to infection status

Discussion. The present study provides clear evidence for a size-related infection of rainbow trout. A similar decrease in prevalence with age was mentioned by Poynton (1986). Whether this is caused by an inadequately developed immune system in smaller fish or is merely due to other physiological conditions in the fry intestine is unknown. In addition, the high stocking density for fry in most hatcheries is likely to increase parasite transmission. Nonetheless, the parasite seems to have a preference for special anatomical and physiological habitats. It prefers the conditions in the anterior part of the intestine including the pyloric region. The expanded microhabitat in heavily infected fish is likely to be caused by a crowding phenomenon (Kennedy 1975) although the presence of parasites in the anterior intestine was interpreted by Moore (1923) as an early infection. However, the possibility cannot be excluded that heavily infected fish possess aberrant

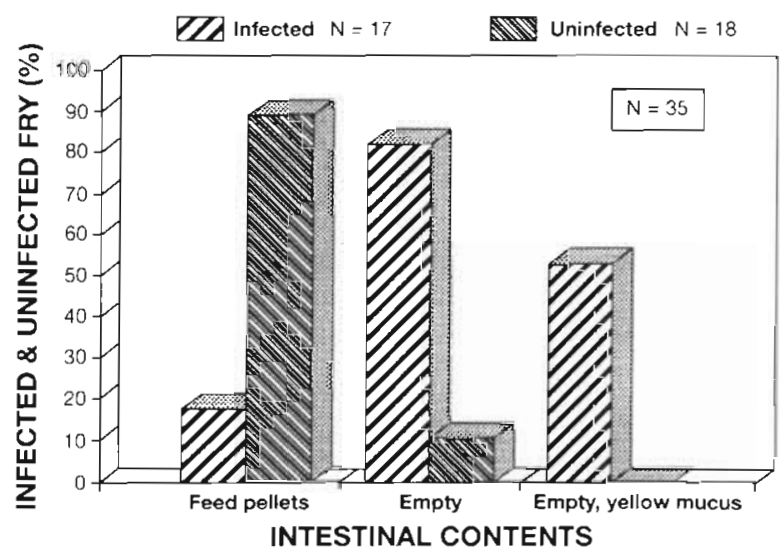

Fig. 4. Hexamita salmonis infecting Oncorhynchus mykiss. Frequencies of food-containing intestines, empty untestines and empty intestines with characteristic yellow mucus in infected and uninfected fish, respectively 
conditions in the posterior intestine which fulfill the growth requirements of Hexamita salmonis. Extraintestinal locations of this flagellate corresponding to the conditions in larger marine salmonids described by Mo et al. (1990), Kent et al. (1992) and Poppe et al. (1992) were not recorded in the present study, and further investigations should be performed to elucidate the relationship between the intestinal and systemic flagellate forms.

A clear association between infection, anorexia and reduced size (weight and length) was provided by these basic data. These studies were performed using only 1 trout stock from 1 particular farm. Similar investigations should be conducted with additional host and farm material. It could still be argued that inferior fry which have reduced appetites and growth rates due to other factors are more susceptible to the infection. Controlled infection experiments were performed by Uzmann et al. (1965) to solve this problem. They actually found a higher morbidity in infected rainbow trout although it was less pronounced in the optimal experimental fish culture conditions used by these authors. It must be emphasized that various strains of this parasite species with different degrees of virulence are likely to exist. The diplomonadid Giardia spp. from humans is comprised of various strains with different characteristics (Thompson et al. 1994). Therefore, these observations lead us to call for new laboratory experiments with the use of relevant parasite strains in order to elucidate this issue.

The prevalent occurrence of yellow mucus in infected fry intestine is interesting. The cause of this pathological state of affairs is not clear but is possibly related to the parasite's effect on bile release into the intestinal lumen, indicating a digestional disorder. The excessive mucus production could be interpreted as the host's reaction to the infection. It has been suggested that increased mucus release from goblet cells (Tse \& Chadee 1991) and increased epithelial turnover (Buret et al. 1990) in the intestinal mucosa are involved in the expulsion of enteric parasites from a variety of hosts.

Acknowledgements. The first presentation concerning this intestinal flagellate was given by Emmeline Moore in September 1922 at the fifty-second annual meeting of the American Fisheries Society. However, the paper was first published (in 1923) in the 1922-1923 edition of the Transactions of the American Fisheries Society. The present study was supported by the Danish Agricultural and Veterinary Research Council and the Elisabeth and Knud Petersen Foundation.

Responsible Subject Editor: W. Körting, Hannover, Germany

\section{LITERATURE CITED}

Buchmann K, Uldal A, Lyholt HCK (1995) Parasite infections in Danish trout farms. Acta Vet Scand 36:283-298

Buret A, Gall DG, Nation PN, Olson ME (1990) Intestinal protozoa and epithelial cell kinetics, structure and function. Parasitol Today 6:375-380

Davis HS (1956) Culture and diseases of game fishes. University of California Press, Berkeley

Ferguson HW (1979) Scanning and transmission electron microscopical observations on Hexamita salmonis (Moore, 1922) related to mortalities in rainbow trout fry Salmo gairdneri Richardson. J Fish Dis 2:57-67

Kent ML, Ellis J, Fournie JW, Dawe SC, Bagshaw JW, Whitaker DJ (1992) Systemic hexamitid (Protozoa:Diplomonadida) infection in seawater pen-reared chinook salmon Oncorhynchus tshawytscha. Dis Aquat Org 14:81-89

Lom J, Dykova I (1992) Protozoan parasites of fishes. Developments in aquaculture and fisheries science 26 . Elsevier, Ansterdam

Mo TA, Poppe TT, Iversen L (1990) Systemic hexamitosis in saltwater reared Atlantic salmon (Salmo salar L.). Bull Eur Ass Fish Pathol 10:69-70

Moore E (1922-1923) Octomitus salmonis, a new species of intestinal parasite in trout. Trans Am Fish Soc 52:74-97

Poppe TT, Mo TA, Iversen L (1992) Disseminated hexamitosis in seacaged Atlantic salmon Salmo salar. Dis Aquat Org $14: 91-97$

Poynton SL (1986) Distribution of the flagellate Hexamita salmonis Moore, 1922 and the microsporidian Loma salmonae Putz, Hoffman and Dunbar, 1965 in brown trout, Salmo trutta L., and rainbow trout, Salmo gairdnen Richardson, in the River Itchen (U.K.) and three of its farms. J Fish Biol 29:417-429

Rosengarten R (1985) Parasitologische Untersuchungen an Regenbogenforellen (Salmo gairdneri Richardson) in einer Forellenteichwirtschaft in Westniedersachsen. DVM Dissertation, Tierärztliche Hochschule Hannover

Thompson RCA, Reynoldson JA, Lymbery AJ (1994) Giardia: from molecules to disease. CAB International, Wallingford

Tse SK, Chadee K (1991) The interaction between intestinal mucus glycoproteins and enteric infections. Parasitol Today 7:163-172

Uzmann JR, Hayduk SH (1963) In vitro culture of the flagellate protozoan Hexamita salmonis. Science 140: $290-292$

Uzmann JR, Paulik GJ, Hayduk SH (1965) Experimental hexamitiasis in juvenile Coho salmon (Oncorhynchus kisutch) and steelhead trout (Salmo gairdneri). Trans Am Fish Soc 94:53-61

Woo PTK, Poynton SL (1995) Diplomonadida, Kinetoplastida and Amoebida (Phylum Sarcomastigophora). In: Woo PTK (ed) Fish diseases and disorders 1. Protozoan and metazoan infections. CAB International, Wallingford

Zitnan R, Cankovic M (1970) Comparison of the epizootiological importance of the parasites of Salmo gairdneri irideus in the two coast areas of Bosna and Herzegovina. Helminthologia 11:161-166

Manuscript first received: September 9, 1995

Revised version accepted: January 1, 1996 